\title{
Arabic Sign Language Recognition
}

\author{
Mahmoud Zaki \\ Abdo \\ Faculty of Engineering, \\ Helwan Uninersity, \\ Cairo, Egypt
}

\author{
Alaa Mahmoud \\ Hamdy \\ Faculty of Engineering, \\ Helwan Uninersity, \\ Cairo, Egypt
}

\author{
Sameh Abd El-Rahman \\ Salem \\ Faculty of Engineering, Helwan \\ Uninersity, Cairo, Egypt
}

\author{
El-Sayed Mostafa \\ Saad \\ Faculty of Engineering, \\ Helwan Uninersity, Cairo, \\ Egypt
}

\begin{abstract}
The objective of the research presented in this paper is to facilitate the communication between the deaf and non deaf people. To achieve this goal, computers should be able to visually recognize hand gestures from image input. An efficient and fast algorithm for gestures of manual Arabic letters for the sign language is proposed. The proposed system uses the concept of hand geometry for classifying letter shapes. Experiments revealed that satisfactory results are obtained via the proposed algorithm. The experiment results show that the gesture recognition rate of Arabic alphabet for different signs is $81.6 \%$
\end{abstract}

\section{General Terms}

Pattern Recognition, Human computer Interaction, Computer Vision.

\section{Keywords}

Sign language recognition, image analysis, hand gestures, hand geometry.

\section{INTRODUCTION}

Normally, there is no problem when two deaf persons communicate using their common sign language. The problem arises when a deaf person wants to communicate with a nondeaf person. Usually both will be unsatisfied in a very short time [1].

Signing has always been part of human communications. For thousands of years, deaf people have created and used signs among themselves. Those signs were the only form of communication available for many deaf people. Within the variety of cultures of deaf people all over the world, signing evolved to form complete languages. Sign language is a form of manual communication and is one of the most natural ways of communication for most people in deaf communities. There has been a surging interest in recognizing human hand gestures.

The aim of the sign language recognition is to provide an accurate and convenient mechanism to transcribe sign gestures into meaningful text or speech so that communication between deaf and hearing society can easily be made.

Sign language is not uniform, but vary from country to country and there effort, research and attempts to unify the sign language of each country separately, such as Egypt, Jordan and Saudi Arabia to help members of the deaf and dumb for each community. [2].

Most of the previous studies on sign languages are based on vision or glove based methods [3]. In the vision based method, the system uses image processing techniques to recognize the gestures without imposing any limitation on the user. While in the glove based method, the user needs to wear special devices, like gloves or markers, to provide the system with data related to the hand shape and motion [4].

Many researchers have been working on hand gestures in many sign languages. Unlike other sign languages such as the American Sign Language (ASL) [5], the Chinese Sign Language (CSL) [6], the Dutch Sign Language, and the Australian Sign Language (Auslan) [7], the Arabic Sign Language (ArSL) has not received a lot of attention [4].

The research work in [2] presented an automatic translation system for gestures of manual alphabets in the Arabic sign language. it does not rely on using any gloves or visual markings. The extracted features phase depends on two stages, edge detection stage and feature-vector-creation stage. it using minimum distance classifier (MDC) and multilayer perceptron (MLP) classifier to detect the 15 characters only.

The rest of the paper is organized as follows. Section two presents an overview on the hand detection. Section three explains the proposed algorithm. Section four explains experimental results. Section five presents the conclusion and future work

\section{Hand detection}

The algorithm uses skin detection with a complex background [13]. The algorithm adopts skin color detection as the first step of skin detection. Due to $\mathrm{YCbCr}$ color space transform, it is faster than other approaches [14], [15]. The algorithm computes the average luminance $\mathrm{Y}_{\text {aveg }}$ of the input image is given in eqn 1.

$$
\mathrm{Y}_{\mathrm{avg}}=\sum \mathrm{y}_{\mathrm{i}, \mathrm{j}}
$$

Where $\mathrm{y}_{\mathrm{i}, \mathrm{j}}=0.3 \mathrm{R}+0.6 \mathrm{G}+0.1 \mathrm{~B}$ should be normalized to the range $(0,255)$, and $i, j$ are the indices of the pixel.

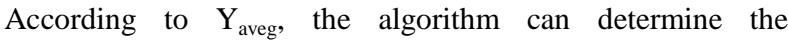
compensated image $\mathrm{Cij}$ by the following equations [13]:

$$
\begin{aligned}
& R_{i, j}^{\prime}=\left(R_{i, j}\right)^{\tau} \\
& G_{i, j}^{\prime}=\left(G_{i, j}\right)^{\tau} \\
& C_{i, j}=\left\{R_{i, j}^{\prime}, G_{i, j}^{\prime}, B_{i, j}\right\}
\end{aligned}
$$

Where

$\tau=\left\{\begin{array}{cc}1.4, & \text { Yaveg }<64 \\ 0.6, & \text { Yaveg }>192 \\ 1, & \text { otherwise }\end{array}\right.$ 


\begin{tabular}{|c|c|c|c|}
\hline $\mathrm{Col} 4$ & Col 3 & Col 2 & Col 1 \\
\hline 14 & 13 & 12 & 11 \\
\hline 24 & 23 & 22 & 21 \\
\hline 34 & 33 & 32 & 31 \\
\hline 44 & 43 & 42 & 41 \\
\hline
\end{tabular}

Fig. 4: 16 zones Hand shape

Note that the algorithm compensates the color of $\mathrm{R}$ and $\mathrm{G}$ to reduce computation. Due to chrominance $(\mathrm{Cr})$ which can represent human skin well, the algorithm only consider $\mathrm{Cr}$ factor for color space transform to reduce the computation. $\mathrm{Cr}$ is defined as follows[13]:

$$
\mathrm{Cr}=0.5 \mathrm{R}^{\prime}-0.419 \mathrm{G}^{\prime}-0.081 \mathrm{~B}
$$

Accordingly, the human skin can be obtained by a binary matrix as follows:

$$
\mathrm{S}_{\mathrm{ij}}=\left\{\begin{array}{cc}
0, & 10<\mathrm{Cr}<45 \\
1, & \text { otherwise }
\end{array}\right.
$$

Where " 0 " is the white point and " 1 " is the black point.

The algorithm implements a filtration by a $5 \times 5$ mask. First, the algorithm segments $\mathrm{Sij}$ into $5 \times 5$ blocks, and calculates how many white points in a block. Then, every point of a $5 \times$ 5 block is set to white point when the number of white points is greater than half the number of total points. Otherwise, if the number of black points is more than a half, this $5 \times 5$ block is modified to a complete black block, as shown in Fig.1 [13].

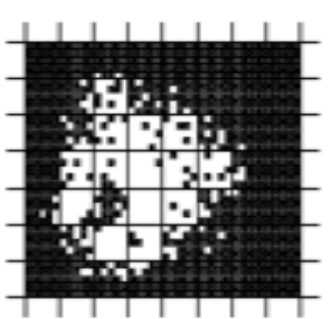

( a )

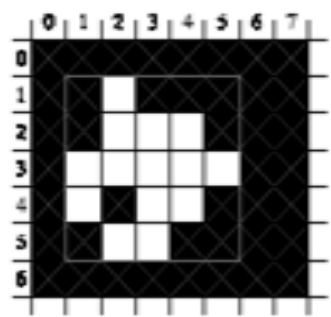

( b )
Fig. 1: (a) An example of Sij (b) removes noise by the $5 \times 5$ filter.

The algorithm using "regionprops" matlab function to measure a set of properties for each connected component (object) in Sij as \{'Area', 'BoundingBox', 'Centroid'\}. The algorithm isolates the ha nd and face as in Fig. 2.
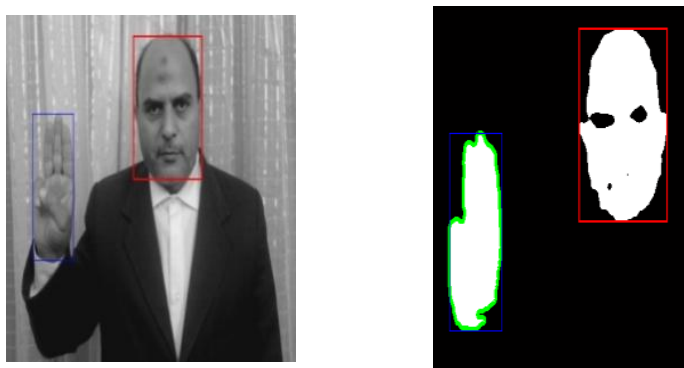

Fig. 2: isolates the hand and face a) gray image b) Blackwhite image with detecting hand contour

Then, the technique in [20] is used to detect the inner circle as shown in Fig. 2. The inner circle represents the palm of the hand.

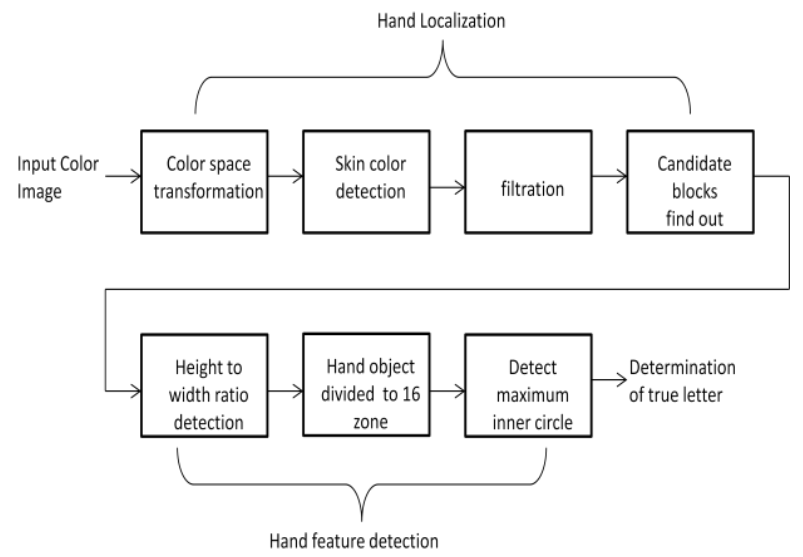

Fig. 3: The flow of proposed method
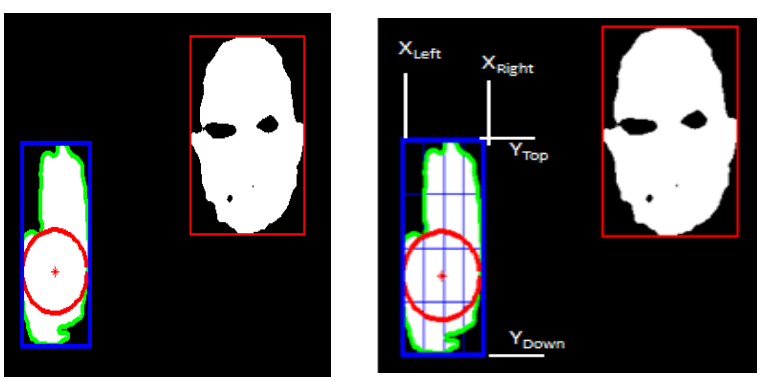

Fig. 5: hand contour detecting and largest inner circle

\section{The proposed Algorithm}

The proposed algorithm divides the rectangle surrounding by the hand shape in Fig. 5 into 16 zones as in Fig. 4.

The proposed algorithm classifies the Arabic sign language alphabets into four classes. It depends on the inner circle position, as follows.

A- Top - Right (T-R) class in which the inner circle is intersecting with top quarter (Row 1) and right side quarter (Col 1) 
B- Top - Not Right (T-NR) class in which the inner circle is intersecting with top quarter (Row 1) and is not intersecting with right side quarter $(\mathrm{Col} 1)$

C- Not Top - Right (NT-NR) class in which the inner circle is not intersecting with top quarter (Row 1) and intersecting with right side quarter (Col 1)

D- Not Top - Not Right (NT-NR) class in which the inner circle is not intersecting with top quarter (Row $1)$ and is not intersecting with right side quarter (Col 1)

Fig. 6 represents the four classes of the arabic letters.

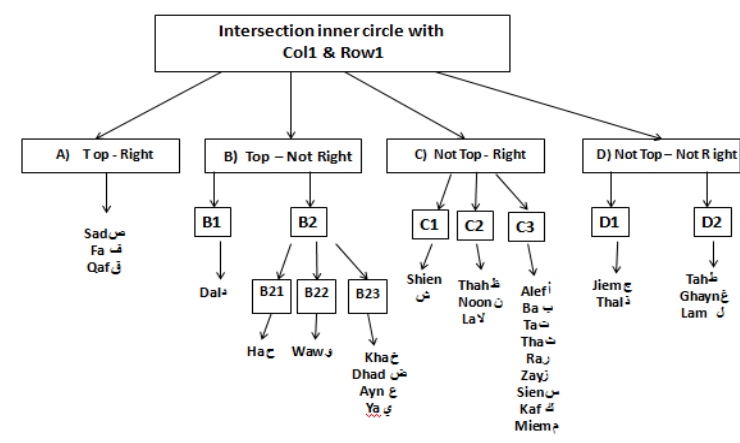

Fig. 6: The classification of letters

\subsection{Top-Right (T-R) class}

In this class, the inner circle is intersecting with the top and right side quarters. It is obvious from Fig. 7 that the three letters $\{\operatorname{Sad} ص, \mathrm{Fa} \omega$, Qaf ق $\}$ the hand palm is closed. Consequently, the inner circle is covering the all sixteen zones including the top and right quarters. In this research work, discrimination of this class can be achieved by computing the centroid of white pixel only in the top quarter and / or the right quarter. However, in order to reduce the computation time, the centroid of top quarter only will be computed, as shown the following algorithm.
ص

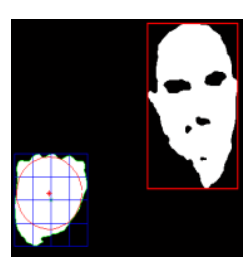

Fa ف
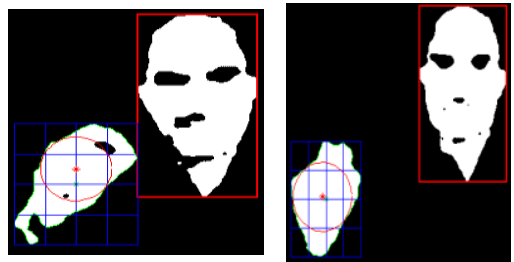

Fig. 7: T - R Letters

\section{$\underline{\text { Top - Right }(T-R) \text { class }}$}

Step 1: Compute the centroid of white pixels in Row 1 for each individual character using the following equation:

$$
\begin{aligned}
& \mathrm{X}_{\mathrm{c}} \leftarrow \frac{1}{\mathrm{~N}}\left[\sum_{\mathrm{y}=\mathrm{y}_{\text {Top }}}^{\mathrm{y}_{\text {Top }}+\mathrm{H} / 4} \sum_{\mathrm{x}=\mathrm{X}_{\text {Left }}}^{\mathrm{X}_{\text {Rig ht }}} \mathrm{x} \quad \text { if } \mathrm{f}(\mathrm{x}, \mathrm{y})=1\right] \\
& \mathrm{Y}_{\mathrm{c}} \leftarrow \frac{1}{\mathrm{~N}}\left[\sum_{\mathrm{y}=\mathrm{y}_{\text {Top }}}^{\mathrm{y}_{\text {Top }}+\mathrm{H} / 4} \sum_{\mathrm{x}=\mathrm{X}_{\text {Left }}}^{\mathrm{X}_{\text {Rig ht }}} \mathrm{y} \quad \text { if } \mathrm{f}(\mathrm{x}, \mathrm{y})=1\right]
\end{aligned}
$$

where, $\mathrm{H}$ is the height of the image, $\mathrm{N}$ is the number of white pixels, and $f(x, y)$ denotes the value of pixel $\{1$ for white pixel and zero for black pixel $\}$

Step 2: Compute the scaled value of $\mathrm{X}_{\mathrm{c}}$ and $\mathrm{Y}_{\mathrm{c}}$

$$
\begin{aligned}
& \mathrm{H}_{\text {Ratio }} \leftarrow 100 \\
& \mathrm{~W}_{\text {Ratio }} \leftarrow \mathrm{H}_{\text {Ratio }} * \mathrm{~W} / \mathrm{H} \\
& \mathrm{X}_{\mathrm{CR}} \leftarrow\left(\mathrm{X}_{\mathrm{C}}-\mathrm{X}_{\text {Left }}\right) * \mathrm{~W}_{\text {Ratio }} / \mathrm{H}_{\text {Ratio }} \\
& Y_{C R} \leftarrow\left(Y_{C}-Y_{\text {Top }}\right) * W_{\text {Ratio }} / H_{\text {Ratio }}
\end{aligned}
$$

Where, $\mathrm{W}$ is the width of the image

Compute the average value $\overline{\mathrm{X}_{\mathrm{cR}}}, \overline{\mathrm{Y}_{\mathrm{cR}}}$ using:

Step 3:

$$
\begin{aligned}
& \overline{\mathrm{X}_{\mathrm{cR}}} \leftarrow \frac{1}{\mathrm{~m}} \sum_{\mathrm{i}=1}^{\mathrm{m}} \mathrm{X}_{\mathrm{cR}_{\mathrm{i}}} \\
& \overline{\mathrm{Y}_{\mathrm{cR}}} \leftarrow \frac{1}{\mathrm{~m}} \sum_{\mathrm{i}=1}^{\mathrm{m}} \mathrm{Y}_{\mathrm{cR}_{\mathrm{i}}}
\end{aligned}
$$

Where $m$ is the number of images of each character.

\subsection{Top - Not Right (T-NR) class}

In this class, the inner circle is intersecting with the top and not intersecting with right side quarters. It is obvious from Fig. 8 that the seven letters $\{$ Ha $ح$, Kha $\dot{\tau}$, Dal د, Dhad ض,

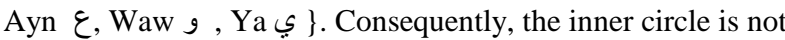
covering the all right quarters. In this paper, discrimination of this class can be achieved as shown the following algorithm. 
Ha ح

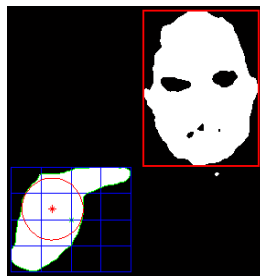

Kha $\dot{\imath}$
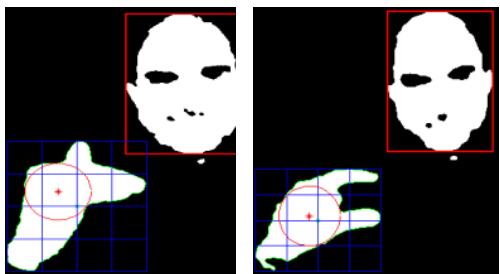

Dhad ض

Ayn $\varepsilon$

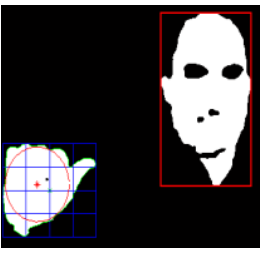

Waw 9

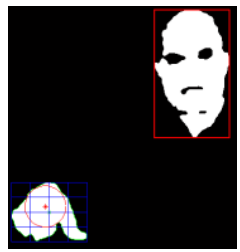

Ya

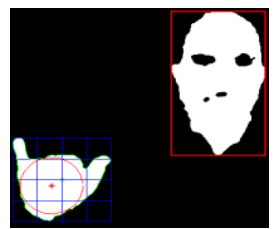

Fig.8: T - NR Letters

\section{Top - Not Right (T - NR) Class}

Step1: Classifying the letters by counting the number of objects in Col 1

Classifier B1: Letter Dal ( د ) has only two objects in the right side (Col 1)

Classifier B2: $\quad$ Letters $\{$ Ha $ح$, Kha $\dot{\tau}$, Dhad ض, Ayn ع, Waw و, Ya $\}$ are one object in the right (Col 1)

Classifier B21: $\quad$ if zones 21,31 and 41 have not white pixels, So the letter is ( $\mathrm{Ha}$ ح )

Classifier B22: $\quad$ if zone 41 have white pixels, So the letter is (Waw 9)

Classifier B23: $\quad$ if not C21 and C22 then compute the centroid of the three characters \{Kha $\dot{\tau}$, Dhad ض, Ayn ع, Ya using the following equation:

$$
\begin{aligned}
& X_{c} \leftarrow \frac{1}{N}\left[\sum_{y=y_{\text {Top }}}^{y_{\text {Down }}} \sum_{x=X_{\text {Right }}-\frac{W}{4}}^{X_{\text {Right }}} x \quad \text { if } f(x, y)=1\right] \\
& Y_{c} \leftarrow \frac{1}{N}\left[\sum_{y=y_{\text {Top }}}^{y_{\text {Down }}} \sum_{x=X_{\text {Right }}-W / 4}^{X_{\text {Right }}} y \quad \text { if } f(x, y)=1\right]
\end{aligned}
$$

Step2: Then Compute the average value $\overline{X_{c R}}, \overline{Y_{c R}}$ using equations ( 7, 8 )

\subsection{Not Top - Right (NT- R) class}

In this class, the inner circle is not intersecting with the top and intersecting with right side quarters. It is obvious from Fig. 9 that The thirteen letters \{Alef $\{$, Ba ب, Ta

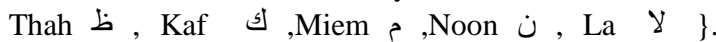
Consequently, the inner circle is not covering the all top 
quarters. In this paper, discrimination of this class can be achieved as shown the following algorithm.

Alef ${ }^{\mathbf{1}}$

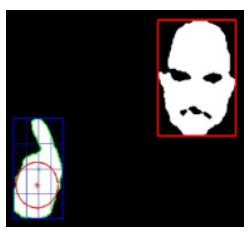

Tha ث

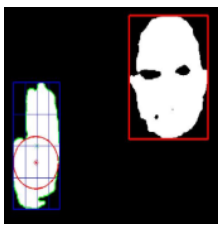

Sien س

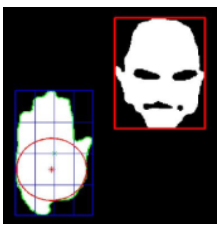

$\mathrm{Ba} \varphi$

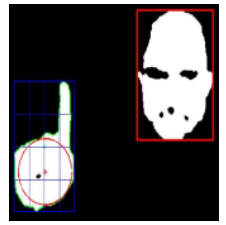

$\mathrm{Ra} J$

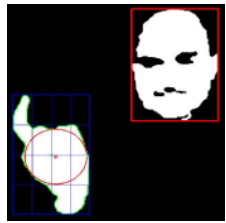

ش

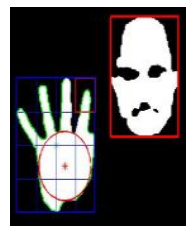

Та

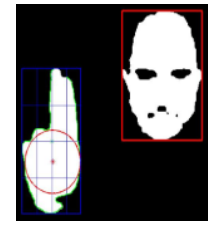

Zay j

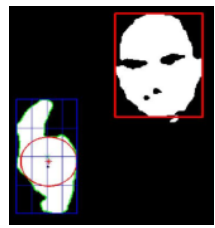

Thah $\dot{b}$

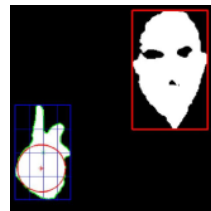

Miem r
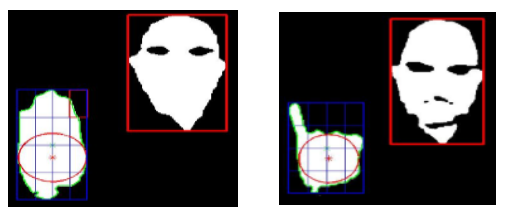

La У

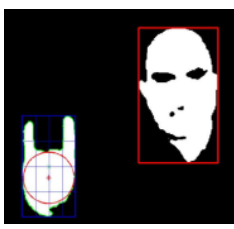

Fig. 9: NT - R Letters

Top Not Right (T NR) Class

Classifying the letters by number of sub object in Row 1

Classifier C1: Letters \{Shien ش ش more than two sub objects in the top (Row1)

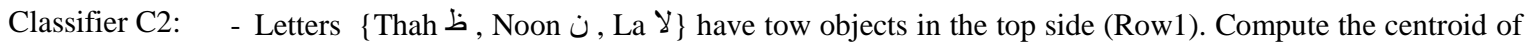
white pixels in Row 1 for each sub object using the following equation:

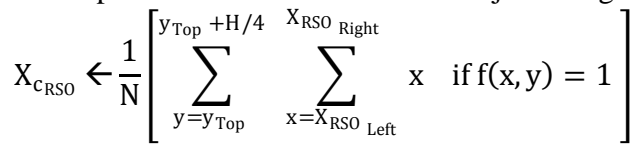

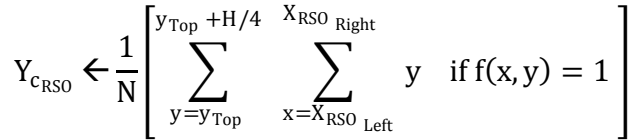

$\mathrm{X}_{\mathrm{c}_{\mathrm{LSO}}} \leftarrow \frac{1}{\mathrm{~N}}\left[\sum_{\mathrm{y}=\mathrm{y}_{\text {Top }}}^{\mathrm{y}_{\text {Top }}+\mathrm{H} / 4} \sum_{\mathrm{x}=\mathrm{X}_{\mathrm{LSO}}}^{\mathrm{X}_{\text {Left }}} \mathrm{x} \quad\right.$ if $\left.\mathrm{f}(\mathrm{x}, \mathrm{y})=1\right]$

$\mathrm{Y}_{\mathrm{c}_{\mathrm{LSO}}} \leftarrow \frac{1}{\mathrm{~N}}\left[\sum_{\mathrm{y}=\mathrm{y}_{\text {Top }}}^{\mathrm{y}_{\text {Top }}+\mathrm{H} / 4} \sum_{\mathrm{x}=\mathrm{X}_{\mathrm{LSO}}}^{\mathrm{X}_{\mathrm{LSO}} \mathrm{R}_{\text {Left }}} \mathrm{y} \quad\right.$ if $\left.\mathrm{f}(\mathrm{x}, \mathrm{y})=1\right]$

Where :

- RSO is Right Sub Object

- LSO is Left Sub Object

Then Compute the average value as using the equations $(7,8)$

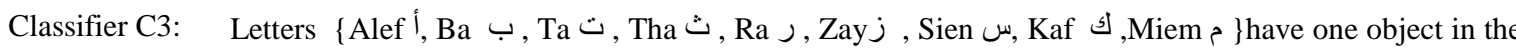
Top (Row1), then using the equations ( 6,7 , and 8 ) 


\subsection{Not Top- Not Right (NT-NR) class}

In this class, the inner circle is not intersecting with the top and not intersecting with right side quarters. It is obvious from Fig. 10 The only five letters \{Jiem ج, Thal ذ, Tah b, Ghayn $\dot{\varepsilon}$, Lam J \}. Consequently, the inner circle is not covering the all top and right quarters. In this paper, discrimination of this class can be achieved as shown the following algorithm.

Jiem ج

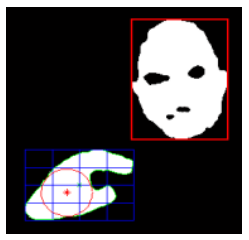

Ghayn $\dot{\varepsilon}$

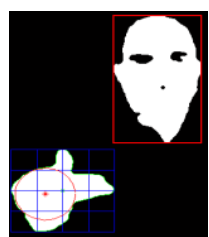

Thal ذ

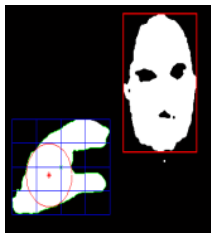

Tah b

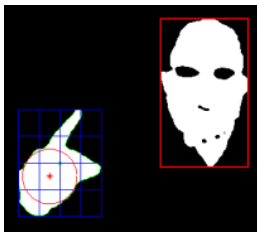

Lam J

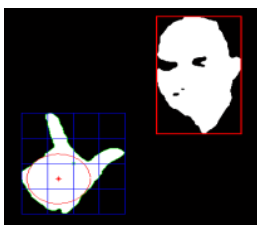

Fig. 10: T R Letters

\section{$\underline{\text { Not Top - Not Right (NT - NR) Class }}$}

Classifying the letters by number of sub objects in Col 1

\section{Classifier D1:}

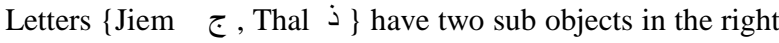
side (Col 1). Compute the centroid of white pixels in Coll for each sub object using the following equation:

$$
\mathrm{X}_{\mathrm{C}_{\mathrm{TSO}}} \leftarrow \frac{1}{\mathrm{~N}}\left[\sum_{\mathrm{y}=\mathrm{y}_{\text {TSO }}}^{\mathrm{y}_{\text {Down }}} \sum_{\mathrm{x}=\mathrm{X}_{\text {Right }}-\mathrm{W} / 4}^{\mathrm{X}_{\text {Right }}} \mathrm{x} \text { if } \mathrm{f}(\mathrm{x}, \mathrm{y})=1\right]
$$$$
\mathrm{Y}_{\text {стSO }} \leftarrow \frac{1}{\mathrm{~N}}\left[\sum_{\mathrm{y}=\mathrm{y}_{\mathrm{TSO}}}^{\mathrm{y}_{\text {Town }}{ }_{\text {Dow }}} \sum_{\mathrm{x}=\mathrm{X}_{\text {Right }}-\mathrm{W} / 4}^{\mathrm{X}_{\text {Right }}} \mathrm{y} \text { if } \mathrm{f}(\mathrm{x}, \mathrm{y})=1\right]
$$

$$
\begin{aligned}
& \mathrm{X}_{\mathrm{C}_{\mathrm{DSO}}} \leftarrow \frac{1}{\mathrm{~N}}\left[\sum_{\mathrm{y}=\mathrm{y}_{\text {DSO }}}^{\mathrm{y}_{\text {Down }}} \sum_{\mathrm{x}=\mathrm{X}_{\text {Right }}-\mathrm{W} / 4}^{\mathrm{X}_{\text {Right }}} \mathrm{x} \text { if } \mathrm{f}(\mathrm{x}, \mathrm{y})=1\right] \\
& \mathrm{Y}_{\mathrm{c}_{\mathrm{DSO}}} \leftarrow \frac{1}{\mathrm{~N}}\left[\sum_{\mathrm{y}=\mathrm{y}_{\text {DSO }}}^{\mathrm{y}_{\text {Down }}} \sum_{\mathrm{x}=\mathrm{X}_{\text {Right }}-\mathrm{Wop} / 4}^{\mathrm{X}_{\text {Right }}} \mathrm{y} \text { if } \mathrm{f}(\mathrm{x}, \mathrm{y})=1\right]
\end{aligned}
$$

- TSO is Top Sub Object

- DSO is Down Sub Object

Then Compute the average value as using the equations $(7,8)$

\section{Classifier D2:}

Letters $\{$ Tah b, Ghayn $\dot{\varepsilon}$, Lam J, Ya ب \}ave one sub object in the right side (Col1), then using the equations ( 9,7 , and 8 )

\section{EXPERIMENTAL}

To evaluate the performance of the proposed system, several images containing Arabic letters have been classified. Several experiments have been conducted. Detecting sub object centroid of each object in top (Row 1) and right (Col 1) depends on the inner circle classifier. Due to the unavailability of a dataset for gestures from Arabic sign language, we had to build our own gestures database. The results as shown in table 1.

\section{CONCLUSION AND FUTURE WORK}

In this paper, a system for the purpose of the recognition and translation of the Arabic letters is designed. The proposed system depends on the inner circle position. The extracted features are scale invariant, which make the system more flexible. Experiments revealed that the proposed system was able to recognize Arabic letters based on the hand geometry.

There is still a lot of further research works in performance improvement considering different descriptors and classifiers. Moreover, additional improvements can be applied for this system to be used for mobile applications to provide easy communication way among deaf people as well as blind and deaf people.

\section{REFERENCES}

[1] A. A.Youssif, Amal Elsayed Aboutabl, Heba Hamdy Ali,"Arabic Sign Language (ArSL) Recognition System Using HMM Aliaa", IJACSA, Volume. 2, No. 11, 2011.

[2] Nashwa El-Bendary, Hossam M. Zawbaa, Mahmoud S. Daoud, Aboul Ella Hassanien, and Kazumi Nakamatsu, "ArSLAT: Arabic Sign Language Alphabets Translator", IJCISIM, Volume 3, 2011, pp. 498-506.

[3] F. Chen, C. Fu and C.,"Hand gesture recognition using a real time tracking method and hidden Markov models", Huang, Image and Vision Computing 21 (March 2003), 745-758.

[4] M. Al-Rousan, O. Al-Jarrah, and M. Al-Hammouri, "Recognition of Dynamic Gestures in Arabic Sign Language using Two Stages Hierarchical Scheme", The International Journal of Intelligent and Knowledge Based Engineering Systems, Volume 14, Number 3, 2010.

[5] T. Starner and A. Pentland, "Visual Recognition of American Sign Language Using Hidden Markov Models ", International Workshop on Automatic Face and Gesture Recognition (June 1995), 189-194.

[6] C.L. Wang, W. Gao and S.G. Shan, "An approach based on phonemes to large vocabulary Chinese sign language recognition", Proceedings of the IEEE International Conference on Automatic Face and Gesture Recognition (2002), 411-416.

Where : 
[7] E.J. Holden, G. Lee and R. Owens, Automatic Recognition of Colloquial Australian Sign Language, IEEE Workshop on Motion and Video Computing 2 (December 2005), 183-188.

[8] J. Ravikiran, Kavi Mahesh, Suhas Mahishi, R. Dheeraj, S. Sudheender, and Nitin V. Pujari, "Automatic Recognition of Sign Language Images", Intelligent Automation and Computer Engineering Lecture Notes in Electrical Engineering Volume 52, 2010, pp 321-332

[9] American Sign Language University http://lifeprint.com/ "

[10] Rafael C. Gonzalez, Richard E. Woods," Digital Image Processing", 2nd Edition,chapter 10, 2001.

[11]E.H. Lockwood," A book of curves",1961

[12] Yeo, Hui-Shyong, Byung-Gook Lee, and Hyotaek Lim. "Hand tracking and gesture recognition system for human-computer interaction using low-cost hardware." Multimedia Tools and Applications (2013): $1-29$.

[13] Pai, Yu-Ting, et al. "A simple and accurate color face detection algorithm in complex background." Multimedia and Expo, 2006 IEEE International Conference on. IEEE, 2006.

[14] S. Gundimada, Li Tao, and v. Asari, "Face detection technique based on intensity and skin color distribution," in 2004 International Conference on Image Processing, Oct. 2004, vol. 2, pp. 1413-1416.

[15] K. P. Seng, A. Suwandy, and L.-M. Ang, "Improved automatic face detection technique in color images," in IEEE Region 10 Conference TENCON 2004, Nov. 2004 vol. 1, pp. 459-462.

[16] Abdo, M. Z., Hamdy, A. M., Salem, S. A. E. R., \& Saad, E. S. M. C30. An Interpolation Based Technique for Sign Language Recognition, NRSC 2013.

[17] Hormann, Kai; AGATHOS, Alexander. The point in polygon problem for arbitrary polygons. Computational Geometry, 2001, 20.3: 131-144.

[18] Deborah, Fenwa Olusayo, Omidiora Elijah Olusayo, and Fakolujo Olaosebikan Alade. "Development of a Feature Extraction Technique for Online Character Recognition System." Innovative Systems Design and Engineering 3.3 (2012): 10-23.

[19] Miyamoto, S., Matsuo, T., Shimada, N., \& Shirai, Y. (2012, November). Real-time and precise 3-D hand posture estimation based on classification tree trained with variations of appearances. In Pattern Recognition (ICPR), 2012 21st International Conference on (pp. 453456). IEEE.

[20] http://www.mathworks.com/matlabcentral/fileexchange/ 30805-maximum-inscribed-circle-using-distancetransform ( Dec. 2013).

Table 1:Expermintal results For arabic alphabets

\begin{tabular}{|c|c|c|c|c|c|c|c|c|c|c|c|c|c|c|c|c|c|c|c|c|c|c|c|c|c|c|c|c|c|}
\hline & 1 & ب & $ت$ & 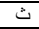 & ? & $\tau$ & $\dot{\tau}$ & 2 & $\dot{j}$ & $J$ & $j$ & س & ش ش & ص & ض & $b$ & $b$ & $\varepsilon$ & $\dot{\varepsilon}$ & ف & ق & 5 & $J$ & $p$ & ن & 9 & $s$ & $\bar{y}$ & $\%$ \\
\hline Alef & 51 & 0 & 43 & 0 & 0 & 0 & 0 & 0 & 0 & 1 & 4 & 1 & 0 & 0 & 0 & 0 & 0 & 0 & 0 & 0 & 0 & 0 & 0 & 0 & 0 & 0 & 0 & 0 & 51 \\
\hline $\mathrm{Ba} 3$ & 0 & $\begin{array}{l}9 \\
7\end{array}$ & 0 & 0 & 0 & 0 & 0 & 0 & 0 & 2 & 0 & 0 & 0 & 0 & 0 & 0 & 0 & 0 & 0 & 0 & 0 & 0 & 0 & 0 & 0 & 1 & 0 & 0 & 97 \\
\hline $\mathrm{Ta} 3$ & 40 & 0 & 45 & 2 & 0 & 0 & 0 & 0 & 0 & 0 & 10 & 3 & 0 & 0 & 0 & 0 & 0 & 0 & 0 & 0 & 0 & 0 & 0 & 0 & 0 & 0 & 0 & 0 & 45 \\
\hline Tha3 & 0 & 0 & 2 & 68 & 0 & 0 & 0 & 0 & 0 & 0 & 0 & 16 & 0 & 0 & 0 & 0 & 0 & 0 & 0 & 0 & 0 & 14 & 0 & 0 & 0 & 0 & 0 & 0 & 68 \\
\hline Geem & 0 & 0 & 0 & 0 & 16 & 0 & 0 & 0 & 0 & 0 & 0 & 0 & 0 & 0 & 0 & 0 & 0 & 0 & 0 & 0 & 0 & 0 & 0 & 0 & 0 & 0 & 0 & 0 & $\begin{array}{r}10 \\
0\end{array}$ \\
\hline $\mathrm{Ha} 3$ & 0 & 0 & 0 & 0 & 0 & 100 & 0 & 0 & 0 & 0 & 0 & 0 & 0 & 0 & 0 & 0 & 0 & 0 & 0 & 0 & 0 & 0 & 0 & 0 & 0 & 0 & 0 & 0 & $\begin{array}{r}10 \\
0 \\
\end{array}$ \\
\hline Kha3 & 0 & 0 & 0 & 0 & 0 & 0 & 36 & 0 & 0 & 0 & 0 & 0 & 0 & 0 & 0 & 0 & 0 & 0 & 0 & 0 & 0 & 0 & 0 & 0 & 0 & 0 & 0 & 0 & $\begin{array}{r}10 \\
0 \\
\end{array}$ \\
\hline Dal & 0 & 0 & 0 & 0 & 0 & 0 & 0 & 100 & 0 & 0 & 0 & 0 & 0 & 0 & 0 & 0 & 0 & 0 & 0 & 0 & 0 & 0 & 0 & 0 & 0 & 0 & 0 & 0 & $\begin{array}{r}10 \\
0 \\
\end{array}$ \\
\hline Thal & 0 & 0 & 0 & 0 & 3 & 0 & 0 & 0 & 13 & 0 & 0 & 0 & 0 & 0 & 0 & 0 & 0 & 0 & 0 & 0 & 0 & 0 & 0 & 0 & 0 & 0 & 0 & 0 & $\begin{array}{r}81 . \\
2 \\
\end{array}$ \\
\hline Ra3 & 7 & 2 & 2 & 0 & 0 & 0 & 0 & 0 & 0 & 47 & 26 & 0 & 0 & 0 & 0 & 0 & 0 & 0 & 0 & 0 & 0 & 0 & 0 & 0 & 0 & 16 & 0 & 0 & 47 \\
\hline Zay & 6 & 0 & 13 & 2 & 0 & 0 & 0 & 0 & 0 & 20 & 47 & 11 & 0 & 0 & 0 & 0 & 0 & 0 & 0 & 0 & 0 & 0 & 0 & 0 & 0 & 1 & 0 & 0 & 47 \\
\hline Seen & 2 & 0 & 2 & 27 & 0 & 0 & 0 & 0 & 0 & 0 & 3 & 52 & 0 & 0 & 0 & 0 & 0 & 0 & 0 & 0 & 0 & 14 & 0 & 0 & 0 & 0 & 0 & 0 & 52 \\
\hline $\begin{array}{c}\text { Shee } \\
n\end{array}$ & 0 & 0 & 0 & 0 & 0 & 0 & 0 & 0 & 0 & 0 & 0 & 0 & 100 & 0 & 0 & 0 & 0 & 0 & 0 & 0 & 0 & 0 & 0 & 0 & 0 & 0 & 0 & 0 & $\begin{array}{r}10 \\
0 \\
\end{array}$ \\
\hline Sad & 0 & 0 & 0 & 0 & 0 & 0 & 0 & 0 & 0 & 0 & 0 & 0 & 0 & 9 & 0 & 0 & 0 & 0 & 0 & 21 & 7 & 0 & 0 & 0 & 0 & 0 & 0 & 0 & $\begin{array}{r}56 . \\
2 \\
\end{array}$ \\
\hline Dad & 0 & 0 & 0 & 0 & 0 & 0 & 0 & 0 & 0 & 0 & 0 & 0 & 0 & 0 & 144 & 0 & 0 & 0 & 0 & 0 & 0 & 0 & 0 & 0 & 0 & 0 & 0 & 0 & $\begin{array}{r}10 \\
0\end{array}$ \\
\hline Da3 & 0 & 0 & 0 & 0 & 0 & 0 & 0 & 0 & 0 & 0 & 0 & 0 & 0 & 0 & 0 & 16 & 0 & 0 & 0 & 0 & 0 & 0 & 0 & 0 & 0 & 0 & 0 & 0 & $\begin{array}{r}10 \\
0 \\
\end{array}$ \\
\hline $\begin{array}{c}\text { Thaa } \\
3 \\
\end{array}$ & 0 & 0 & 0 & 0 & 0 & 0 & 0 & 0 & 0 & 0 & 0 & 0 & 0 & 0 & 0 & 0 & 93 & 0 & 0 & 0 & 0 & 0 & 0 & 0 & 0 & 0 & 0 & $\begin{array}{l}2 \\
8 \\
\end{array}$ & $\begin{array}{r}76 . \\
8 \\
\end{array}$ \\
\hline Aien & 0 & 0 & 0 & 0 & 0 & 0 & 0 & 0 & 0 & 0 & 0 & 0 & 0 & 0 & 0 & 0 & 0 & 144 & 0 & 0 & 0 & 0 & 0 & 0 & 0 & 0 & 0 & 0 & $\begin{array}{r}10 \\
0 \\
\end{array}$ \\
\hline Ghain & 0 & 0 & 0 & 0 & 0 & 0 & 0 & 0 & 0 & 0 & 0 & 0 & 0 & 0 & 0 & 0 & 0 & 0 & 16 & 0 & 0 & 0 & 0 & 0 & 0 & 0 & 0 & 0 & $\begin{array}{r}10 \\
0 \\
\end{array}$ \\
\hline fa3 & 0 & 0 & 0 & 0 & 0 & 0 & 0 & 0 & 0 & 0 & 0 & 0 & 0 & 0 & 0 & 0 & 0 & 0 & 0 & 16 & 0 & 0 & 0 & 0 & 0 & 0 & 0 & 0 & $\begin{array}{r}10 \\
0 \\
\end{array}$ \\
\hline Kaaf & 0 & 0 & 0 & 0 & 0 & 0 & 0 & 0 & 0 & 0 & 0 & 0 & 0 & 6 & 0 & 0 & 0 & 0 & 0 & 0 & 10 & 0 & 0 & 0 & 0 & 0 & 0 & 0 & $\begin{array}{r}62 . \\
5\end{array}$ \\
\hline Kaf & 0 & 0 & 0 & 22 & 0 & 0 & 0 & 0 & 0 & 0 & 0 & 13 & 0 & 0 & 0 & 0 & 0 & 0 & 0 & 0 & 0 & 65 & 0 & 0 & 0 & 0 & 0 & 0 & 65 \\
\hline Laam & 0 & 0 & 0 & 0 & 0 & 0 & 0 & 0 & 0 & 0 & 0 & 0 & 0 & 0 & 0 & 2 & 0 & 0 & 0 & 0 & 0 & 0 & 14 & 0 & 0 & 0 & 0 & 0 & $\begin{array}{r}87 . \\
5 \\
\end{array}$ \\
\hline Mee & 0 & 2 & 0 & 0 & 0 & 0 & 0 & 0 & 0 & 14 & 8 & 0 & 0 & 0 & 0 & 0 & 0 & 0 & 0 & 0 & 0 & 0 & 0 & 76 & 0 & 0 & 0 & 0 & 76 \\
\hline
\end{tabular}


International Journal of Computer Applications (0975 - 8887) Volume 89 - No 20, March 2014

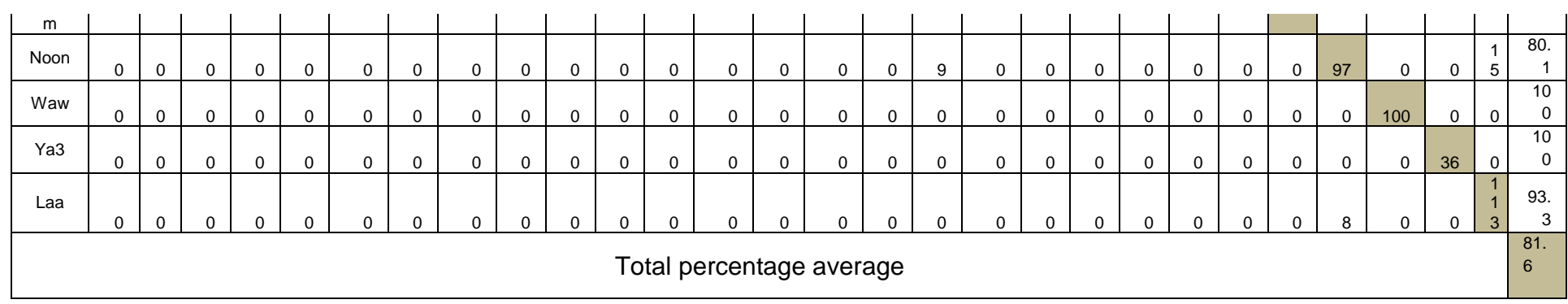

